\title{
Endoscopic ultrasound-guided placement of plastic pigtail stents for the drainage of refractory malignant ascites $\square$
}

\section{(ㄷ)(우우}

\author{
Authors \\ Rafael Romero-Castro', Victoria Alejandra Jimenez-Garcia', Jaime Boceta-Osuna², Luis Castilla-Guerra², Francisco \\ Pellicer-Bautista ${ }^{1}$, Angel Caunedo-Alvarez ${ }^{1}$, Juan Manuel Herrerias-Gutierrez ${ }^{1}$, Manuel Romero-Gómez ${ }^{1}$, Marc \\ Giovannini $^{3}$
}

Institutions

1 Gastroenterology Service, Virgen Macarena University Hospital, Seville, Spain

2 Department of Internal Medicine, Virgen Macarena University Hospital, Seville, Spain

3 Endoscopy Unit, Institut Paoli-Calmettes, Marseilles, France

submitted 5.7.2017

accepted after revision: 24.7.2017

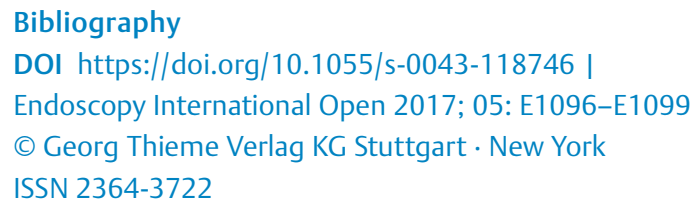

Corresponding author

Rafael Romero-Castro, MD, PhD, Gastroenterology Service, Virgen Macarena Hospital, Avd. Doctor Fedriani, 3, 41009

Seville, Spain

Fax: +34-955-008805

rafaromecas@hotmail.com

\begin{abstract}
Endoscopic ultrasound (EUS)-guided drainage is now the treatment of choice in cases of pancreatic pseudocysts and walled-off necrosis, especially in the absence of luminal bulging and in patients with portal hypertension. Malignant refractory ascites usually heralds a poor prognosis and substantially impairs the quality of life of patients because of the symptoms experienced and the need for repeated paracentesis. EUS-guided placement of lumen-apposing, fully covered, self-expandable metal stents (FCSEMS) has been reported for the drainage of malignant ascites. Herein, we present the results of EUS-guided placement of plastic pigtails stents for the drainage of refractory malignant ascites in three patients. The aim was to improve symptoms and minimize the possible drawbacks of large-caliber FCSEMS. In this preliminary experience, EUS-guided placement of plastic stents was feasible and avoided further paracentesis.
\end{abstract}

\section{Introduction}

Malignant ascites appears in up to $50 \%$ of neoplastic processes. It is a poor prognostic sign, except in the case of ovarian cancer. Malignant ascites impairs the patient's daily living activities owing to the distressing symptoms as well as to the palliative procedures, mainly repeated intermittent paracentesis, needed to evacuate the fluid, which readily re-accumulates. Other invasive treatments are available, such as different permanent internal or external catheters; these methods avoid repetitive paracentesis, but may be associated with severe adverse events.

Endoscopic ultrasound (EUS)-guided drainage of pancreatic pseudocysts and walled-off necrosis, especially in the absence of luminal bulging and in patients with portal hypertension, should be preferable to other procedures that not use ultrasound guidance [1]. Since the first cases were reported [2], lu- men-apposing, fully covered, self-expandable metal stents (FCSEMSs) have been increasingly employed in the drainage of pseudocysts and walled-off pancreatic necrosis. In addition, three cases of malignant ascites drained by EUS-guided placement of lumen-apposing FCSEMSs have been reported [3].

Herein, we report our results from three patients with malignant refractory ascites who underwent EUS-guided placement of plastic pigtail stents for drainage into the stomach. Our aims were symptomatic relief, avoiding repeated paracentesis and the possible drawbacks of FCSEMSs such as hemodynamic and electrolyte imbalance, and preventing leakage of gastric contents into the peritoneum. 
- Table 1 Results of endoscopic ultrasound-guided placement of plastic pigtail stents for the drainage of malignant refractory ascites into the stomach.

\begin{tabular}{|c|c|c|c|c|c|c|c|}
\hline Case & $\begin{array}{l}\text { Age, } \\
\text { years }\end{array}$ & Cause of ascites & $\begin{array}{l}\text { Karnofsky/ } \\
\text { ECOG index }{ }^{1}\end{array}$ & $\begin{array}{l}\text { Outcome (need } \\
\text { for further } \\
\text { paracentesis) }\end{array}$ & $\begin{array}{l}\text { Adverse } \\
\text { events }\end{array}$ & $\begin{array}{l}\text { Surveillance } \\
\text { after drainage, } \\
\text { days }\end{array}$ & Cause of death \\
\hline 1 & 60 & B-cell lymphoma & $70 / 2$ & No & $\begin{array}{l}\text { Pneumoperi- } \\
\text { toneum }\end{array}$ & 42 & $\begin{array}{l}\text { Nephrotoxicity }{ }^{2} \\
\text { Oncological progression }\end{array}$ \\
\hline 2 & 74 & $\begin{array}{l}\text { Liver cirrhosis, } \\
\text { HCC }\end{array}$ & $40 / 3$ & No & No & 10 & $\begin{array}{l}\text { End-stage CKD } \\
\text { Liver failure } \\
\text { Oncological progression }\end{array}$ \\
\hline 3 & 55 & $\begin{array}{l}\text { Liver cirrhosis, } \\
\text { HCC }\end{array}$ & $30 / 4$ & Yes $^{3}$ & No & 6 & $\begin{array}{l}\text { Liver failure } \\
\text { Oncological progression }\end{array}$ \\
\hline
\end{tabular}

ECOG, Eastern Cooperative Oncology Group; CKD, chronic kidney disease; HCC, hepatocellular carcinoma; OP, oncologic progression.

${ }^{1}$ Karnofsky and ECOG index before admission and procedure.

${ }^{2}$ After new line chemotherapy.

${ }^{3} \mathrm{~A}$ second plastic pigtail stent had to be inserted alongside the first stent.

\section{Case series}

Written informed consent was obtained after carefully discussing the experimental nature of the procedure with patients and their relatives. All patients had been previously diagnosed with malignant ascites after cytological analyses of the ascites. They received $2 \mathrm{~g}$ amoxicillin plus clavulanic acid before the procedure, and continued oral antibiotics for 5 days after the procedure. Clinical features and patient outcomes are presented in - Table 1.

\section{Case 1}

A 60-year-old man with progressive, stage IV, marginal zone, Bcell malignant lymphoma who was undergoing rescue chemotherapy, was admitted for massive ascites with abdominal pain, dyspnea, and severe cytopenia. He had required six evacuation paracentesis procedures in the previous 2 weeks.

EUS-guided drainage of ascites was performed as follows. After flushing the working channel of the therapeutic echoendoscope (EG-3870UT; Pentax, Tokyo, Japan) with povidone-iodine (Meda Pharma, Solna, Sweden), the greater gastric curvature was punctured with a 19-G needle (Cook Endoscopy, Limerick, Ireland), and a 0.035 -inch guidewire was inserted into the ascites. To create a fistula between the gastric cavity and the ascites, balloon dilators up to $8 \mathrm{~mm}$ (Boston Scientific, Cork, Ireland) were used. Then, a $10 \mathrm{Fr}$ plastic pigtail stent (Cook Endoscopy) was placed. In this first case, a 10-Fr cystostome (Cook Endoscopy) was employed because the balloon dilator cannot transverse the gastric wall. After this prolonged procedure, a clinically significant pneumoperitoneum was observed, and was resolved after puncturing the abdominal wall with a 14- $G$ catheter. No other adverse events were observed. The patient was discharged 6 days later and no more paracentesis were needed. The patient developed chemotherapy-related nephrotoxicity and died 6 weeks later.

\section{Case 2}

A 74-year-old man with end-stage chronic kidney disease, liver cirrhosis, and hepatocellular carcinoma, who was unfit for curative treatment, was admitted for hepatic encephalopathy and refractory malignant ascites. At admission, laboratory parameters showed hepatic and renal malfunction, including thrombocytopenia (platelets $44 \times 10^{9} / \mathrm{L}$ [normal value $150-400 \times$ $\left.10^{9} / \mathrm{L}\right]$ ), urea $194 \mathrm{mg} / \mathrm{dL}$ (normal value $7-20 \mathrm{mg} / \mathrm{dL}$ ), creatinine $6.4 \mathrm{mg} / \mathrm{dL}$ (normal value $0.8-1.4 \mathrm{mg} / \mathrm{dL}$ ), potassium $5.9 \mathrm{mEq} / \mathrm{L}$ (normal value $3.5-5.0 \mathrm{mEq} / \mathrm{L}$ ), and metabolic acidosis. After the endoscopic procedure described above using a $10 \mathrm{Fr}$ cystostome ( $\vee$ Fig. 1, - Video 1 ), a good clinical response was obtained. No adverse events were observed after the procedure. No more paracentesis were needed, and the patient's clinical condition improved. However, 10 days later he died from renal failure and severe coagulopathy associated with end-stage liver disease.

\section{Case 3}

A 55-year-old man with chronic kidney disease, liver cirrhosis, and multicentric hepatocellular carcinoma stage $C$, who was unfit for surgical resection or liver transplantation, was admitted for malignant refractory ascites with respiratory insufficiency and hydrothorax. After undergoing the procedure described above using a $10 \mathrm{Fr}$ cystostome, no adverse events were observed and clinical improvement was achieved. However, 1 week later the patient experienced a rapid increase in abdominal girth. Another plastic pigtail stent was inserted alongside the first stent. The patient died 6 days later due to progression of the oncological disease and liver failure.

\section{Discussion}

Except in the case of ovarian cancer, malignant ascites carries a poor prognosis as a manifestation of terminal metastatic disease. Refractory ascites is defined when it cannot be mobilized, shows early recurrence, and cannot be avoided by medical therapy [4]. Ascites substantially impairs a patient's quality of life 

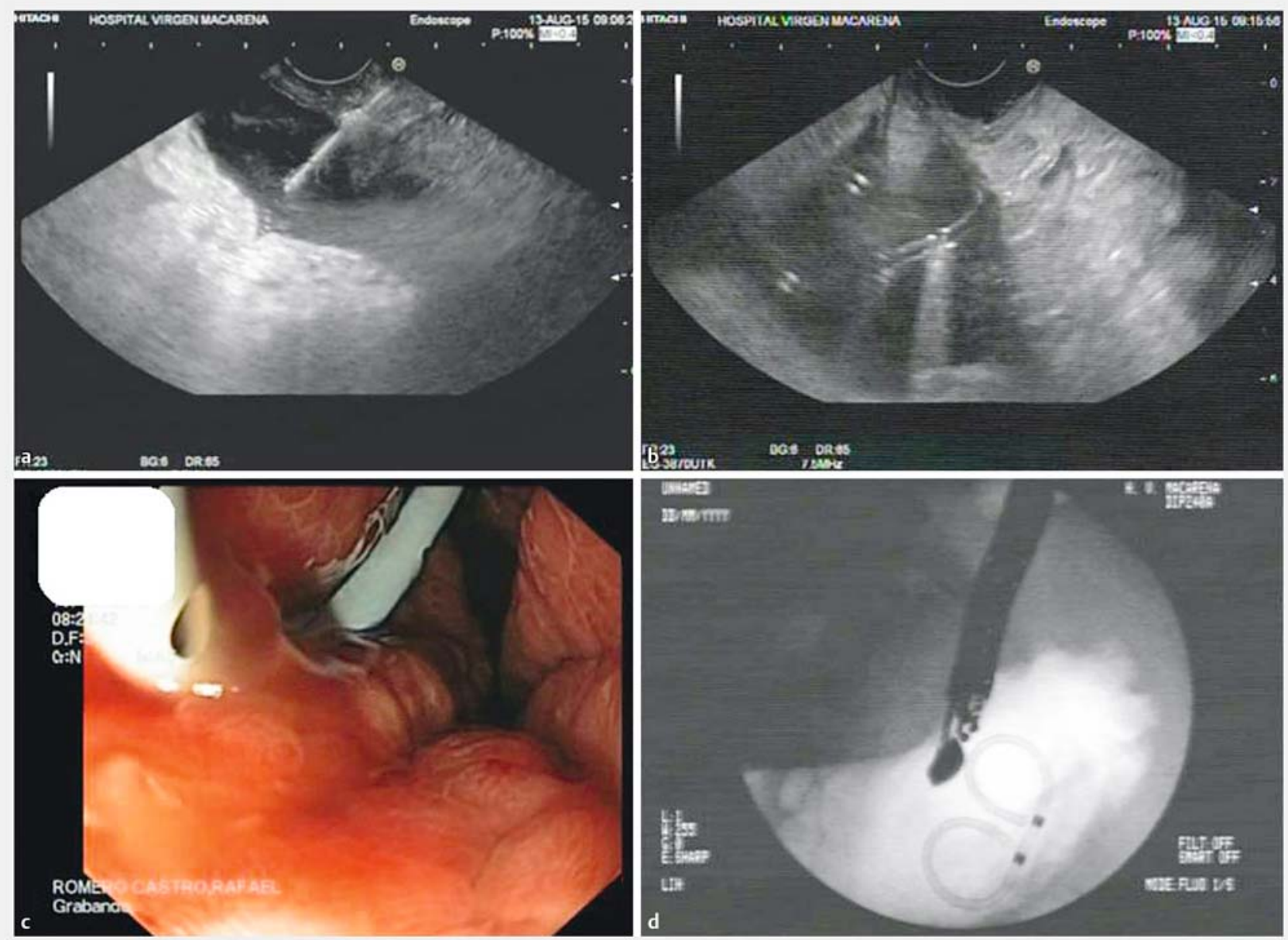

- Fig. 1 Endoscopic ultrasound (EUS)-guided stent placement for drainage of malignant ascites. a EUS-guided puncture of the ascites with the needle part of a $10 \mathrm{Fr}$ cystostome, transversing the greater curvature of the stomach. $\mathbf{b}$ The $10 \mathrm{Fr}$ plastic double-pigtail stent was observed by endosonography in the ascites. $\mathbf{c}$ Endoscopic view of the plastic stent draining the ascites into the gastric cavity. $\mathbf{d}$ Fluoroscopic view of the plastic double-pigtail stent.

owing to its distressing symptoms and the invasive procedures needed to evacuate the accumulated fluid. Diuretics are ineffective, and repeated paracentesis is the most employed drainage method, resulting in rapid symptomatic relief. However, the risk of hemorrhage and sepsis exists, and the process can lead to formation of loculated ascites, increasing the risk of bowel wall injury and reducing the efficacy of the procedure. To ensure amenability to paracentesis, the procedure is usually delayed until the ascites is tense, further worsening the symptoms and quality of life of the patient.

Alternative, more invasive, drainage options to avoid repeated paracentesis are indwelling catheters for external drainage [5] or internal drainage, such as peritoneo-gastric [6], peritoneo-cystic [7], peritoneo-venous [8], and transjugular intrahepatic portosystemic shunts (TIPS) [9]. All of these procedures may require frequent visits to the hospital for severely ill patients and specialized care of the devices. Studies of these drainage methods have yet to define outcomes and complications, and further therapeutic results with validated patientrelated outcomes are needed to compare between several drainage methods [10]. Moreover, there are a lack of guidelines and randomized studies to guide clinical decision making. Therefore, the management of refractory malignant ascites in the context of palliative care should be addressed to improve patient quality of life and minimize potential adverse events.

Symptomatic relief and technical success have been reported previously for three cases of malignant ascites drained throughout lumen-apposing FCSEMS deployed under EUS guidance [3]. However, in this paper, the authors stated that because of the large caliber of these stents, several potential drawbacks, such risk of migration, occlusion by food or debris, and leakage of gastric content into the peritoneum, could occur. Therefore, the authors modified the technique by placing multiple plastic pigtail stents inside the FCSEMS in order to create a physical barrier to solid particles. Other possible drawbacks of FCSEMSs could be hemodynamic and electrolytic imbalances, and ascites infection. Safe drainage of fluid collections, walled-off pancreatic necrosis, and mediastinal and abdominal abscesses has been reported. In all of these established procedures, a fistulous tract is deliberately created be- 
tween the digestive tract and the mediastinum, peritoneum or retroperitoneum, and maintained by one or several plastic or large-caliber metal stents. One particular advantage of the lumen-apposing FCSEMS is that, thanks to their wider caliber compared with plastic stents, the orifice of the fistula is larger and the communication between the digestive tract and the collection should remain patent. Our main goal was symptomatic relief to improve the patients' quality of life, avoiding repeated paracentesis, and to test whether plastic pigtails stents could be sufficient for the purpose of draining ascites to alleviate symptoms, with any remaining ascites serving as a buffer to prevent free passage of air to the peritoneal cavity, thus avoiding the potential drawbacks of large-caliber FCSEMS.

All patients were in very poor clinical condition, and only short survival periods were observed after the procedures. In the first case, a symptomatic pneumoperitoneum was resolved after puncturing the abdominal wall with a $14 \mathrm{G}$ catheter. Although placement of plastic stents may produce pneumoperitoneum and can lead to bacterial colonization of the ascites, the procedure is the same as for the treatment of walled-off pancreatic necrosis. In one patient, another pigtail stent was deployed alongside the first stent following re-accumulation of fluid due to relapse, probably reflecting the need for specific stents in this setting.

As only a small number of patients were included in this study and their survival was short, issues such as efficacy and safety cannot be evaluated from these results and more studies are needed to define the key points related to EUS-guided drainage of malignant ascites. It also needs to be born in mind that adverse events related to stent insertion are difficult to distinguish from the advanced comorbidity of these patients. In patients with end-stage liver cirrhosis, as in cases 2 and 3, it is justified to perform other invasive procedures, such as TIPS

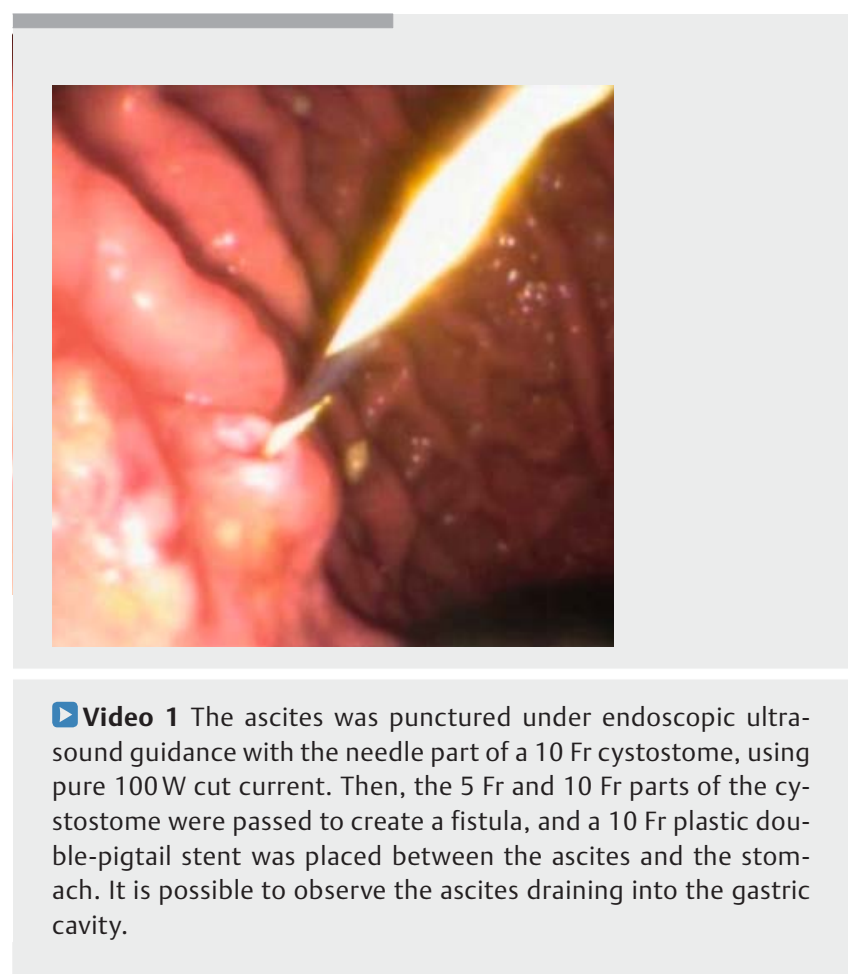

for the treatment of portal hypertension, despite the increased risk of adverse events.

Our local Institutional Review Board has approved a prospective study to clarify the safety and effectiveness of draining refractory malignant ascites in patients with an expected survival of $>3$ months (JBO-ECO-2017-01). It is hoped that the results of this study will lead to improvement in end-of-life palliative therapy, alleviating symptoms and reducing the need for frequent visits to the hospital and the use of healthcare resources.

\section{Competing interests}

None

\section{References}

[1] Fusaroli P, Jenssen C, Hocke M et al. EFSUMB guidelines on interventional ultrasound (INVUS), Part V - EUS-guided therapeutic interventions (short version). Ultraschall Med 2016; 37: 412-420

[2] Itoi T, Binmoeller KF, Shah J et al. Clinical evaluation of a novel lumenapposing metal stent for endosonography-guided pancreatic pseudocyst and gallbladder drainage (with videos). Gastrointest Endosc 2012; 75: $870-876$

[3] Musumba C, Tutticci N, Nanda K et al. Endosonography-guided drainage of malignant fluid collections using lumen-apposing, fully covered self-expanding metal stents. Endoscopy 2014; 46: 690-692

[4] Saada E, Follana P, Peyrade F et al. [Pathogenesis and management of refractory malignant ascites]. Bull Cancer 2011; 98: 679-687

[5] O'Neill M], Weissleder R, Gervais DA et al. Tunneled peritoneal catheter placement under sonographic and fluoroscopic guidance in the palliative treatment of malignant ascites. AJR Am J Roentgenol 2001; 177: $615-618$

[6] Lorentzen T, Sengelov L, Nolsoe CP et al. Ultrasonically guided insertion of a peritoneo-gastric shunt in patients with malignant ascites. Acta Radiol 1995; 36: 481 - 484

[7] Stehman FB, Ehrlich CE. Peritoneo-cystic shunt for malignant ascites. Gynecol Oncol 1984; 18: 402-407

[8] Arai Y, Inaba Y, Sone M et al. Phase I/II study of transjugular transhepatic peritoneovenous venous shunt, a new procedure to manage refractory ascites in cancer patients: Japan Interventional Radiology in Oncology Study Group 0201. AJR Am J Roentgenol 2011; 196: W621-626

[9] Burger JA, Ochs A, Wirth K et al. The transjugular stent implantation for the treatment of malignant portal and hepatic vein obstruction in cancer patients. Ann Oncol 1997; 8: 200-202

[10] Christensen L, Wildgaard L, Wildgaard K. Permanent catheters for recurrent ascites - a critical and systematic review of study methodology. Support Care Cancer 2016; 24: $2767-2779$ 